\title{
A transcendência divina e a angústia humana no livro VII das Confissões de Agostinho
}

\author{
Luiz Marcos da Silva Filho \\ Orientador: Prof. Dr. Moacyr Novaes \\ $\mathrm{CNPq}$
}

O objetivo deste trabalho é examinar o desespero e a angústia humana em relação à transcendência e à presença de Deus. Inicialmente, será analisada a Carta XVIII, de Agostinho, para que se explicite o problema do aparente paradoxo existente na concepção de um absoluto transcendente e presente no mundo. Essa questão está desenvolvida no livro VII das Confissões, no qual é possível observar uma tentativa de resposta. Será notável que desespero, angústia e esperança se alternam na trajetória de Agostinho para solucionar aquela questão, noções essas indissociáveis da busca agostiniana pelo ser supremo.

O começo da Carta XVIII diferencia três modos de natureza: o corpo, a alma e Deus, conforme a mutabilidade de cada um no espaço e no tempo. Deus é o único "que nem o espaço nem o tempo podem mudar" ${ }^{1}$ Em outras palavras, logo de início é declarado existir um abismo ontológico entre naturezas mutáveis e uma imutável. Porém, em seguida, é constatada uma ponte nesse abismo porque é dito que

${ }^{1}$ AGOSTINHO. Carta XVIII. 
Deus, imutável, "chama-se Criador", e o que é mutável, o corpo e a alma, "chama-se criatura", 2 isto é, há uma relação de criador-criatura entre o absoluto e o relativo.

A continuidade da carta diz que "uma coisa é... enquanto permanece e é uma", ${ }^{3}$ e que por isso se pode ver a "distinção das naturezas" ${ }^{4}$ Essa distinção ocorre devido a uma hierarquização ontológica. Deus é considerado "o que é de maneira suprema", ${ }^{5}$ o corpo está no "último degrau de ser", 6 e a alma no degrau intermediário, acima do corpo, abaixo de Deus. Assim, o que não é o ser supremo é quase-ser, define-se por uma tensão entre o ser e o não-ser, pois as coisas que estão abaixo do imutável "absolutamente não existem, nem totalmente deixam de existir" e "só existe realmente aquilo que permanece imutável" 7

Encontrando-se em uma condição de quase-ser, imersa na multiplicidade, a alma poderia desesperar-se. Ela, entretanto, tem motivos para não se desesperar, visto que pode ter esperança de se aproximar do ser que é realmente. Ora, "o Ser supremo é a felicidade mesma", e "o degrau intermediário se torna miserável se sua vida tende para o que está embaixo, torna-se feliz se tende para o Ser supremo".

Tal aproximação é possível porque Cristo torna quem crê nele "apto para se fixar no Ser supremo", o que é um motivo a mais para a alma não se desesperar, já que não só pode se aproximar do ser que é verdadeiramente, como é o próprio ser que oferece a mediação, no caso, expressa por sua encarnação.

\footnotetext{
2 Idem. Carta XVIII.

3 Ibidem

4 Ibidem

${ }^{5}$ Ibidem

6 Ibidem

7 Idem. Confissões, VII, 11, 17.

8 Ibidem

9 Ibidem
} 
Desse modo, retira-se da carta a seguinte questão: como é possível que Deus se engaje no mundo sem se contaminar com a multiplicidade para salvar o homem, fazendo-o alçar o ser a partir do devir? "Agostinho freqüentemente se perguntou. A angústia latente sob a dialética das Confissões não exprime outra coisa que essa inquietude humana"10

O esclarecimento dessa questão será efetuado por intermédio do exame dos modos pelos quais são apresentadas as respectivas soluções e em que termos elas realmente são solucionadoras. Isso ensejará a análise da articulação de desespero, angústia e esperança. $\bigcirc$ exame dessa articulação mostrará que ocorrem dois sentidos de angústia. Um, em um primeiro momento, causado pela ausência da salvação e, por conseqüência, de esperança, de modo que ocorre junto com o desespero. Outro, em um segundo momento, não mais acompanhado pelo desespero, pois é causado por aquilo que motiva a esperança.

No início do Livro VII, Agostinho faz uma hierarquização de naturezas, conforme a mutabilidade delas, de maneira semelhante ao que ocorre no início da Carta XVIII. "Eu te considerava incorruptível, inviolável, imutável, pois... estava certo de que tudo aquilo que é sujeito à corrupção é certamente inferior àquilo que não o é. E o que não é passível de corrupção, sem hesitação eu o colocava acima daquilo que é passível. Então compreendia: o que é imutável é melhor do que aquilo que pode mudar"11

Logo após, Agostinho analisa a forma pela qual ele concebia e imaginava Deus. Sua concepção era materialista, pois Deus era concebido corporalmente. Ele tentava ver Deus em sua transcendência, sendo imutável, infinito, e presente. Mas nota a limitação dessa concepção para enfrentar questões como a do mal.

${ }^{10}$ GILSON. E. Philosophie et Incarnation selon saint Augustin. p. 26.

${ }^{11}$ Idem. Confissões, VII, 1, 1. 
Eu fazia de tuas criaturas uma enorme e única massa [...]. E essa massa eu a imaginava imensa..., embora limitada de todos os lados, envolta e de todas as partes penetrada por ti, Senhor, que permanecias infinito em todas as direções, como um mar que, em toda parte e por todos os lados, formaria um mar imenso, estendendo-se infinitamente na imensidade, contendo dentro de si uma esponja enorme, porém limitada e toda embebida desse mar imenso ${ }^{12}$.

Agostinho assinala as conseqüências contraditórias dessa concepção, tais como ter que aceitar que "uma parte maior da terra deveria conter uma parte maior" de Deus, "ao passo que a menor conteria parte menor". O mesmo ocorreria com "o corpo do elefante" que "possuiria uma parte" de Deus "maior que a de um pardal, por ser maior e ocupar maior espaço"13

Ademais, a limitação dessa concepção ocorre na medida em que não há espaço para ver o mal no todo, pois "Deus é bom, poderosíssimo... sendo bom, criou coisas boas, e assim as envolve e completa. Mas então onde está o mal, de onde veio e como conseguiu penetrar? Qual a sua raiz, qual a sua semente?"14.

Dessa forma, não há uma concepção clara de Deus em sua relação com o homem; a concepção que há apresenta dificuldades, contradições, absurdos. É por isso que Agostinho diz: "eu tentava arrancar o meu espírito do abismo, mas afundava de novo, e, apesar dos reiterados esforços, afundava muitas e muitas vezes"15 $\mathrm{e}$ "tais eram as reflexões que agitavam meu pobre espírito, já sob o peso da pungente preocupação de morrer sem conseguir descobrir a verdade" 16 .

Ou seja, Agostinho se debate em meio à angústia e ao desespero por não ver com clareza como a unidade, o absoluto, engaja-se na

\footnotetext{
${ }^{12}$ Ibidem, VII, $5,7$.

${ }^{13}$ Ibidem, VII, 1, 2.

${ }^{14}$ Ibidem, VII, 5, 7.

${ }^{15}$ Ibidem, VII, 3, 5.

${ }^{16}$ Ibidem, VII, $5,7$.
} 
multiplicidade, no relativo. Ora, se esse engajamento não for visto claramente, também não é visível a possibilidade de salvação, de um repouso, de se safar da multiplicidade, da dispersão. Ocorre, assim, um primeiro sentido de angústia, que é o referente à ausência da salvação, à inexistência de razões para ter esperança e não desespero.

Até aqui, verificou-se que a questão haurida da Carta XVIII não foi resolvida. Talvez ela tenha sido aprofundada como elaboração na tentativa de resolvê-la, contudo, sem êxito. Contatou-se, dessa maneira, a complexidade do problema, o desespero que ele ocasiona, e como não deve ser resolvido, a saber, com imagens corpóreas. Além disso, e por isso, foi constatada a limitação da inteligência humana.

Em conseqüência, a resolução da questão só ocorrerá com uma outra concepção de Deus. E é o que, com muito esforço, Agostinho faz. Esta outra concepção lhe permitirá ver a relação de Deus com o homem, e com a criação em geral, sem contradiçōes.

Vi uma luz imutável. [...]. Não era uma luz como esta, mas totalmente diferente das luzes desta terra. Também não estava acima de minha mente como o óleo sobre a água nem como o céu sobre a terra, mas acima de mim porque ela me fez, e eu abaixo porque fui feito por ela [...]. E eu disse: "Porventura deixará de existir a verdade, por não ser uma realidade difusa pelos espaços finitos e infinitos"? E tu me gritaste de longe: "Na verdade, eu sou aquele que sou"17.

Essa outra concepção tem como fundamento a redefinição da infinitude divina e da finitude das criaturas. Trata-se da redefinição que levará o absoluto a ser considerado como determinante e indeterminado. Deus é infinito "mas de outro modo" ${ }^{18}$, é infinito porque é aquilo que é, o ser supremo. Todas "as outras coisas devem a existência a ti e são todas limitadas em ti, porém de modo diferente,

17 Ibidem, VII, 10, 16; Ex 3, 14.

${ }^{18}$ Ibidem, VII, 14, 20. 
não no espaço: na verdade, tu tens todos como na palma da mão"19 Ou seja, Deus é o limite de todas as coisas porque ele, ao criar, determina, só que não espacialmente, e sim ontologicamente.

Isso fica mais claro pela razão com que Agostinho prefere usar o vocábulo essência, em detrimento do vocábulo substância, com relação a Deus. "Deus é, sem dúvida, uma substância ou (se o termo for mais adequado) uma essência.... Assim como a palavra 'sabedoria' vem do verbo conhecer com sabor (sápere) e 'ciência' procede do verbo saber (scire), assim, 'essência' é termo derivado do verbo ser (esse)"20. Da mesma forma que a palavra sabedoria é o grau máximo de saber, que reúne em si todos os saberes, essência também é o grau máximo, no caso, de ser.

Conseqüentemente, tal como as almas, "para serem sábias, são renovadas pela participação na sabedoria que permanece por si"21, todos os seres têm ser pela participação no ser supremo. E Deus é a "eterna verdade, verdadeira caridade e cara eternidade"22 porque é o fundamento determinante de todas as áreas, conforme a divisão clássica, do saber. Como eternidade é determinante da física, uma vez que esta investiga as coisas que são, que têm ser, e o supremo ser é eterno. Como caridade é determinante da ética, e como verdade é da lógica. Como todas as coisas existentes estão incluídas em alguma dessas áreas do saber, Deus determina tudo.

Em resumo, a redefinição de infinitude divina leva o $\mathrm{ab}$ soluto a ser considerado infinito, indeterminado, porque nada pode determiná-lo. E é determinante porque determina, ontologicamente, tudo o que existe.

Por intermédio da análise dessas redefinições, soluciona-se parte da questão retirada da Carta XVIII, uma vez que já é sabida a ma-

\footnotetext{
${ }^{19}$ Ibidem, VII, 15, 21.

${ }^{20}$ Idem, A Trindade, V, 2, 3.

${ }^{21}$ Idem, Confissões, VII, 9, 14.

${ }^{22}$ Ibidem, VII, 10, 16.
} 

riores são melhores que as inferiores, o conjunto de todas é ainda melhor"26. Por conseqüência, o mal - ausência de ser -, que Deus determinou ao determinar o grau de ser de cada coisa, desempenha um papel bom no âmbito do todo, já que contribui para que "cada coisa se" harmonize, "não só com seu lugar, mas também com sua época"27

No homem, o mal não é somente ausência de ser. Sendo Deus, que é o sumo bem, o único princípio de toda a criação, este não pode ser a causa da maldade, iniqüidade, praticada pelo homem. Por conseqüência, só resta o ser humano como "causa do mal" ${ }^{28}$ que ele mesmo pratica. Logo, o homem tem livre-arbítrio para voltar sua vontade ou para as coisas que têm mais ser, ou para as que têm menos. Em outros termos, se o livre-arbítrio do homem não fosse concebido, Deus teria que ser considerado a origem do mal.

A livre determinação da vontade humana, dessa maneira, permite ver a iniqüidade não como "substância existente em si, mas a perversão da vontade que, ao afastar-se do Ser supremo... se volta para as criaturas inferiores; e, esvaziando-se por dentro, pavoneia-se exteriormente"29

O homem, assim, determina sua vontade ao decidir se quer voltar-se para a dispersão, dispersando seu ser, ou se quer manter-se próximo do ser supremo. Aliás, "os justos são tanto mais parecidos com os elementos superiores da criação, quanto mais se tornam semelhantes a" ${ }^{30}$ Deus. Ou melhor, há a possibilidade de o homem diminuir sua mutabilidade tentando se preencher de ser, tentando uma maior participação, semelhança, com o ser verdadeiro.

Essa possibilidade, no entanto, só existe porque o absoluto a estabelece, já que seria absurdo e também, de acordo com o vocabu-

\footnotetext{
${ }^{26}$ Ibidem, VII, 13,19.

${ }^{27}$ Ibidem, VII, 15, 21.

${ }^{28}$ Ibidem, VII, 3, 5.

${ }^{29}$ Ibidem, VII, 16, 22.

${ }^{30}$ Ibidem, loc. cit.
} 
lário agostiniano, um exemplo de soberba, considerar que uma natureza mutável efetue alguma mediação com uma imutável. "Eu buscava um meio que me desse forças para gozar de ti, mas não o encontraria, enquanto não aderisse 'ao mediador entre Deus e os homens, o homem Cristo Jesus, que acima de todas as coisas é o Deus'”31.

Melhor dizendo, Agostinho precisa considerar, entre outras razões, a existência da mediação porque a concepção de Deus, como aquele que é, é tributária a ela. Ou seja, se não houvesse uma mediação não teria sido possível superar a concepção de Deus como infinitude corporal, ou qualquer outra concepção que também tenha conseqüências absurdas por caracterizar o absoluto com o uso de imagens corpóreas, com características mutáveis das criaturas. E, logicamente, uma das conseqüências disso seria a constatação de que o ser humano estaria fadado a se dispersar, e a se desesperar, ao estar sem saída imerso na multiplicidade.

Mas, por haver uma mediação, Agostinho viu Deus como luz imutável não sensível. Com efeito, pôde ultrapassar sua inteligência. "Instigado... a retornar a mim mesmo, entrei no íntimo do meu coração sob tua guia, e o consegui, porque tu te fizeste meu auxílio. Entrei e, com os olhos da alma, acima destes meus olhos e acima de minha própria inteligência, vi uma luz imutável. Não era essa luz vulgar e evidente a todos com os olhos da carne" ${ }^{132}$.

Poder-se-ia argumentar contra Agostinho, considerando-se que os platônicos, por exemplo, não precisaram de uma mediação, entre eles e o absoluto, para este ser concebido. Possivelmente, o bispo de Hipona responderia que, na verdade, eles precisaram de uma mediação, mas não a admitiram por serem soberbos ${ }^{33}$.

Uma vez concebido Deus como ser supremo, criador e fundamentação de tudo o que existe, vê-se que tudo tem uma relação de

\footnotetext{
${ }^{31}$ Ibidem, VII, 18, 24; 1Tm 2, 5; Rm 9, 5.

${ }^{32}$ Ibidem, VII, 10, 16.

${ }^{33}$ Cf. Ibidem, VII, 20, 26; 21, 27.
} 
a eternidade, que, por definição, pois é mutável no tempo, não poderia conceber. É nesse sentido que Agostinho diz que o Verbo "junta à carne aquele alimento que eu não era capaz de tomar. (...) De fato, o teu Verbo... eleva a si os que lhe são sujeitos... e assim faz que se arranquem de si mesmos aqueles que aceitam a submissão"41

Em suma, a questão retirada das afirmaçōes da Carta XVIII é solucionada pela redefinição de infinitude divina, a qual redunda na concepção do supremo ser, mantendo-se imutável, como fundamento ontológico de tudo o que existe, o que ocorre pela noção de participação, que é constante enquanto algo existe. Além disso, vislumbrou-se a necessidade da encarnação do absoluto para que Agostinho ultrapasse sua inteligência e possa se aproximar do ser.

É possível, no entanto, analisar essa "solução" ao recolocar o problema da carta em outros termos, e não o solucionando. Ora, concebida uma ponte salvífica, agora cabe ao homem outra enorme tarefa, que é a de passar por essa ponte.

A mediação, a existência da ponte, ocorre de maneira descendente, ou seja, do imutável oferecendo ao mutável a possibilidade de ascensão, de aumento de ser, o que não poderia ser de outra forma. Pelo fato de existir uma mediação, Agostinho tem razões para ter esperança. Contudo, não sem angústia, pois a mediação é descendente, o que faz com que o caminho da salvação seja estreito (angustus).

Diferentemente daquela primeira acepção de angústia, agora ocorre uma segunda. Na primeira acepção, a angústia ocorria por causa da ausência da esperança, e acompanhada pelo desespero. Nessa segunda, ela ocorre por causa da existência da esperança, e, por isso, sem o desespero. Ou seja, as razões da esperança conferem angústia, o que pode propiciar a esta um valor positivo, diferente do da primeira acepção.

Ora, devido ao fato de a mediação ser descendente, e de ter se expressado, entre outros modos, pela encarnação do absoluto - que

${ }^{41}$ Idem, op. cit., VII, 18, 24. 
fez com que os homens "se sentissem fracos ao ver a seus pés a divindade tornada fraca, porque participante de nossa veste carnal"42 - o homem, o quase-ser, pode verificar o quão distante está de um absoluto que é de tal maneira imutável que se engajou na multiplicidade sem mudar. E por causa dessa distância (o homem) não consegue vêlo, e deve se colocar "no caminho que leva a" Deus, "para que ... possa ver e possuir" ${ }^{43}$ Essa distância, impedimento para se ver Deus, pôde ser observada no esforço que Agostinho efetuou para conceber o absoluto de modo não corpóreo.

Esse caminho espiritual, para que se "possa ver e possuir" Deus, pode ser definido como sendo, no mínimo, a prática da humildade, pois Deus mesmo se humilhou e, assim, é exemplo para que "aquele que crê em Cristo... não se" glorifique "por ser mediano" 44 entre o corpo e o ser supremo. Também pôde ser observado o imperativo da humildade ao homem ao se constatar a limitação de sua inteligência e a necessidade de se elevar acima de si para conceber a infinitude divina.

Portanto, a "solução", que é a redefinição de infinitude divina e a encarnação, à questão retirada da Carta XVIII, recoloca uma outra questão, que é o modo pelo qual o homem deve trilhar o caminho em direção a Deus. Assim, se por um lado, essa "solução", que concebe a maneira como o homem pode se safar da multiplicidade, não permite o desespero, e ocasiona esperança, por outro lado, a própria condição dispersiva do homem e o modo como a mediação foi efetuada (descendentemente) oferecem dificuldades para que ele se coloque em um caminho que leve a uma menor dessemelhança com a unidade, dificuldades essas que permitem a agonia e a angústia. Ou seja, a ponte salvífica que existe no abismo entre o quase-ser e o ser é estrei-

\footnotetext{
${ }^{42}$ Ibidem, loc. cit.

${ }^{43}$ Ibidem, VII, 21, 27.

${ }^{44}$ Idem, Carta XVIII.
} 
ta, o que confere uma esperança angustiante, afinal, quando o transcendente é descoberto presente, torna-se ainda mais transcendente.

\section{Bibliografia consultada}

AGOSTINHO, A. A cidade de Deus (contra os pagãos). Petrópolis: Vozes, 1990. . A Trindade, São Paulo: Paulus, 1995.

. A verdadeira religião. São Paulo: Paulinas, 1987.

. Confissōes, São Paulo: Paulus, 2002.

. Confessions, Paris: Les Belles Lettres, 1990.

Lettre XVIII, France: Editions Ad Solem, 1999.

. O livre-arbítrio. Col. Patrística, São Paulo: Paulus, 1994.

ARENDT, H. O conceito de amor em Santo Agostinho. Trad. A. P. Dinis. Lisboa: Instituto Piaget, 1997.

GILSON, E. Introduction l'étude de saint Augustin, Paris: Vrin,1943.

. "Linfinité divine chez saint Augustin". In: Congres International Augustinien, Augustinus Magister I: 569-574. Etudes Augustiniennes, Paris, 1954.

. "Notes sur l'être et le temps chez saint Augustin" Recherches Augustinienne II, p. 205-23. Etudes Augustiniennes, Paris, 1962. 1999.

. Philosophie et Incarnation selon saint Augustin, France: Editions Ad Solem,

HADOT, P. "La notion d'infini chez saint Augustin" Philosophie (26), p. 59-72. Paris, 1990.

van BAVEL, T. "Lhumanité du Christ comme lac parvulorum et comme via dans la spiritualité de saint Augustin". Augustiniana 7 (1954) p. 245-81. 